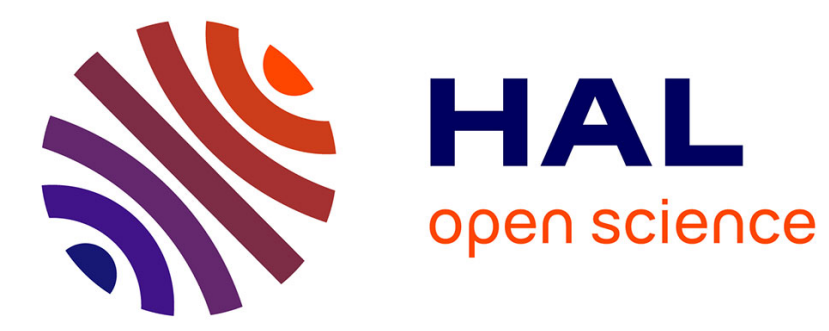

\title{
On the role of protases in conditional statements: Some evidence from Hindi
}

Ghanshyam Sharma

\section{To cite this version:}

Ghanshyam Sharma. On the role of protases in conditional statements: Some evidence from Hindi. Rajendra Singh \& Ghanshyam Sharma. Annual Review of South Asian Languages and Linguistics, Mouton de Gruyter, pp.49 - 78, 2011, ISBN 978-3-11-027057-0. 10.1515/9783110270655.49 . hal01402323

\section{HAL Id: hal-01402323 \\ https://hal-inalco.archives-ouvertes.fr/hal-01402323}

Submitted on 24 Nov 2016

HAL is a multi-disciplinary open access archive for the deposit and dissemination of scientific research documents, whether they are published or not. The documents may come from teaching and research institutions in France or abroad, or from public or private research centers.
L'archive ouverte pluridisciplinaire HAL, est destinée au dépôt et à la diffusion de documents scientifiques de niveau recherche, publiés ou non, émanant des établissements d'enseignement et de recherche français ou étrangers, des laboratoires publics ou privés. 


\title{
On the role of protases in conditional statements: Some evidence from Hindi*
}

\author{
Ghanshyam Sharma
}

Providing evidence from Hindi, the present study determines the crucial role played by the protasis (or antecedent or P-clause) in the actualization of conditional constructions. It maintains that tense-aspect-mood elements of the protasis establish different degrees of hypotheticality in a conditional statement. The paper questions some widespread misunderstandings about the clause ordering in conditional constructions, namely that conditionals can exhibit both the protasis-apodosis $(P-Q)$ and apodosis-protasis $(Q-P)$ orderings. By examining data from Hindi and making reference to data from other languages, the paper reiterates our earlier claim that protasis-apodosis ordering in conditional constructions cannot be reversed and advances a new idea that a 'conditional string' is the defining characteristic of a conditional construction. In other words, it is either the proposition contained in the apodosis - not the entire apodosis - which is preposed by the speaker to accomplish different communicative tasks, or the entire 'conditional string' which is added to a non-conditional statement to give it conditional dimensions.

\section{Overview}

Despite being a most extensively studied subject, conditionals still remain a hotly debated topic - both in philosophy and linguistics - largely due to the peculiarity of these constructions. The present paper looks into the crucial role played by the protasis (i.e. P-clause, antecedent, subordinate clause or dependent clause $)^{1}$ in the overall structure of conditional constructions. It discusses certain evidence from Hindi to determine the role played by the tense-aspect-mood (TAM hereafter) elements in the classification of conditional statements. In addition, it makes yet again an attempt to reiterate that protasis-apodosis (i.e. P-Q) ordering is the only possible clause order in natural languages. Thus, the paper rejects the idea that con- 
ditionality may be expressed through apodosis-protasis ordering. As an additional point, the paper puts forward a new theory which - however bizarre it might seem at first glance - may have some implications for different brands of syntactic analyses. The basic idea is that in a conditional statement the conditionality is introduced exclusively by a conditional string which stretches from the protasis marker, if in English, up through what is generally considered to be an apodosis marker, i.e. then or [Ø], in English. This conditional string, in my view, is the sole factor in the actualization of a conditional statement, to which can be attached any kind of proposition in a language, thus generating wide varieties of conditional statements. In this manner, the paper argues that the attachment of a conditional string (i.e. protasis plus the so-called apodosis marker) to the apodosis proposition should not be viewed as analogous with the attachment of an adverbial clause to the main clause (as is common in most brands of syntactic analyses) nor should there be a need to propose two different kinds of attachments, one for the sentence-initial protasis (namely as IP/CP adjunction) and the other for the sentence-final protasis (namely as VP adjunction). ${ }^{2}$

\section{What is a conditional statement?}

It is a widely accepted belief that conditional statements are complex sentences built up from two constituent clauses: the first being the if-clause and the second the then-clause. However, given the diverse syntactic varieties of conditional statements attested in different languages, it proves difficult, if not impossible, to give a clear-cut definition which might encompass all the characteristics of conditional statements. To begin with, it is generally assumed that conditional statements may have either an overt or a covert marking of two clauses. Besides, it is also commonly believed that they may overtly mark just one of the two clauses or may exhibit the same marker in both clauses. On the other hand, conditional statements are reported to be employed in situations where they convey quasi-conditional meanings rather than real hypothetical meanings. ${ }^{3}$ Furthermore, there are documented cases of reduced and pseudo-conditionals ${ }^{4}$ across the languages in which conditional statements may have either a covert protasis or a covert apodosis in the common ground. Realizing this difficulty, Declerck and Reed (2001: 9) have devised a general definition which tries to cover the basic characteristics of English conditionals, namely, "a conditional is a two-clause structure in which one of the clauses is introduced by if (pos- 
sibly preceded by only, even or except) or except if (viz. unless)." Needless to say, this definition too is inadequate and says almost nothing about the 'conditionalhood' of English conditionals, let alone the characteristics of conditionals in general. Moreover, the mere presence or absence of the protasis marker in a statement cannot be the sole basis for considering a statement conditional since, as mentioned above, there are languages which do not obligatorily mark the protasis and others which do not mark either of the two clauses. Thus, I argue that it is the conditional string (viz. 'if- then' ..., or, to put it in non-English terms, ' $\alpha-\beta$ '...) - with or without overt markers - which is the defining characteristic of a conditional statement. According to this view, a conditional string is to be regarded as equipped with what others have taken to be the markers of two clauses either overtly or covertly - and can be attached to any clause (viz. an assertion, an order, a question, etc.) of a language to fashion it into an apodosis clause in a conditional statement, as in (1)-(5)

(1) [If you heat water to 100 degrees celsius, Ø] it boils.

(2) [If it rains this afternoon, Ø] everybody will stay home.

(3) [If I become President, Ø] I'll lower taxes.

(4) [If it's raining now, then] your laundry is getting wet.

(5) [If it's raining now, then] don't go outside.

where the conditional string - which contains all the elements between square brackets - consists of the protasis and either a null marker $\varnothing$ or the overt marker then. As is clear from examples (1), (2) and (3), the conditional string in English may contain a null marker [Ø] as well. As a consequence, only the remaining part of the statement - which lies outside the square brackets - is to be considered an apodosis proposition. Without entering into the syntactic details of the argument, we claim that for an adequate analysis of conditionals, any syntactic theory has to take into account the concept of the conditional string rather than dividing a conditional statement into two traditionally established parts (i.e. the if-clause and the then-clause), basically following conventional wisdom. The conditional string, in my view, is the sole factor which renders a statement a conditional statement. The protasis, thus, is the founding clause rather than a dependent or subordinate clause in a conditional statement, as has wrongly been assumed in most of the literature on conditionals. ${ }^{5}$ We reject the orthodox division of a conditional statement into two separate entities:

[[If-PROPOSITION] [then-PROPOSITION]] 
in which then proform is heedlessly considered to be a marker of the apodosis and thus is considered to be an integral part of it. We rather propose the division of a conditional statement along the following lines:

$$
\text { [[If-PROPOSITION then] [-PROPOSITION]] }
$$

In this way, it can be said that a conditional statement is a statement which obligatorily contains the conditional string. The conditional string induces the hearer to suppose a case which is different than the case present in the common ground and thus introduces an alternative situation to the discourse. In semantic terms, the conditional string is the sole means of introducing conditionalhood to any sentence type in a language. Borrowing truth-conditional semantics terminology, it can be stated that a conditional string creates a suppositional world - a possible world - which is different from the actual world and in which the proposition contained in the apodosis has to be true. Using Fauconnier's (1994) terminology, it can be said that the conditional string sets up a mental space wherein the content of an apodosis (an assertion, an imperative, an interrogative, etc.) is understood to exist. Moreover, in terms of mental model theory, it can be said that the conditional string serves as a basis for constructing a mental model of the state of affairs from which the conclusion in the apodosis has to be drawn. ${ }^{6}$ As stated above, the conditional string may introduce various meanings into a conditional statement. For example, it may serve as a premise in inferential or hypothetical conditionals or it can create a situation in which the speaker has to deliver his or her illocutions in the apodosis, producing the so-called speech-act conditional. To sum up, the conditional string hypothetically may be equipped either with both of the markers or just one of them.

\section{The position of the protasis in a conditional statement}

In this section we make an attempt to determine the exact position of the protasis in a conditional statement, thus providing some evidence in support of our earlier claim (Sharma 2010), namely that in a conditional statement there may be the protasis-apodosis ordering only. As is widely reported, Greenberg (1963: 66) in his Universal of Word Order 14 states that: "In conditional statements, the conditional clause precedes the conclusion as the normal order in all languages.” Indeed, numerous studies have suggested that the protasis-apodosis clause order is in fact the univer- 
sal order as it has a resemblance to the order of human reasoning and furthermore shows "parallels between order of elements in language and order of elements in experience". ${ }^{7}$ In spite of this universally accepted fact, it is also acknowledged that many languages seem to exhibit the apodosisprotasis ordering as well. In fact, the abundance of data displaying the apodosis-protasis ordering in world languages has led linguists to believe that the protasis in final position indicates an after-thought on the part of the speaker. Another speculative argument goes as follows: "Given that it seems to be commoner cross-linguistically for the protasis to be marked overtly as non-factual than for the apodosis to be so marked ..., placing the overtly marked protasis in front of the unmarked apodosis avoids the apodosis being interpreted as a factual statement" (Comrie 1986: 84). As I maintain elsewhere (Sharma 2010), contrary to the widely-held belief, I show that no language seems to exhibit a marked apodosis in the sentenceinitial position. In other words, there is no evidence of any sort to demonstrate that a language may indeed have the apodosis-protasis ordering in conditionals. Broadly speaking, the apodosis marking is considered to be done through a proform - generally a resumptive pronoun or a time adverbial - such as then in English. However, as will become clear from our subsequent discussion, we do not consider then to be an apodosis marker. Furthermore, there are no data from any language to suggest that the socalled sentence-initial apodosis can ever be marked, either overtly or covertly. According to our line of reasoning, the protasis is the basis of a conditional string which includes the so-called apodosis marker as well. Thus, the idea that the protasis may follow the apodosis is simply untenable and misleading.

Let us now develop some further arguments in support of our hypothesis. In different typological studies it has been extensively reported that most languages overtly mark either the protasis or the apodosis, or both (Comrie 1986; Xrakovskij 2005). Following this line of thought, we can postulate the following four hypothetical types of clause combinations under which all languages can be classified.
a. [Overtly marked P $\quad+$ Overtly marked Q]
b. [Overtly marked P $\quad+$ Non overtly marked Q]
c. [Not overtly marked P + Overtly marked Q]
d. [Not overtly marked P + Not overtly marked Q]

No language seems to exclusively belong to just one of the above four categories. As mentioned in the previous section, some overtly mark both the 
protasis and the apodosis (8a), others mark either the protasis (8b) or the apodosis (8c) and there may also be languages without any means to overtly mark either of the two. Furthermore, even if a language has at its disposal the means to overtly mark both the protasis and the apodosis, it may or may not obligatorily employ them. For example, English and Hindi apparently have means to overtly mark both the protasis and the apodosis, but English obligatorily marks the protasis only whereas Hindi obligatorily requires the use of the particle to (i.e. then) to express conditionality, which is generally considered to be the marker of the apodosis. Likewise, Mandarin is reputed to have the means to mark both clauses, but unlike English and Hindi, it is reported to not mark them obligatorily. In fact Mandarin may allow both the protasis and the apodosis to remain unmarked. Thus, bearing in mind the obligation or non-obligation for overt marking in the protasis and the apodosis, we can revise the list of different types of combinations expressed in (8), and hypothetically have four different categories, as in (9)

(9) a. [Obligatorily marked P

b. [Obligatorily marked $\mathrm{P}$

+ Obligatorily marked Q]

c. [Non-obligatorily marked $\mathrm{P}$

d. [Non-obligatorily marked $\mathrm{P}$

+ Non-obligatorily marked Q]

+ Obligatorily marked Q]

+ Non-obligatorily marked Q]

As mentioned above, languages such as English, French and Italian are reported to obligatorily mark the protasis and thus can be said to belong to the category in (9b), whereas Hindi - and presumably many other IndoAryan languages as well - can be considered to belong to the category in (9c) since it does not mark the protasis obligatorily and requires the apodosis to be marked obligatorily. Mandarin, on the other hand, does not require any clauses to be obligatorily marked and therefore should be included in the category in (9d). Now, let us examine the above four classes, one by one, to check if indeed our argument can be proved valid.

\subsection{Class 1: Obligatorily marked $\mathrm{P}+$ Obligatorily marked Q}

Only reliable data from this group of languages could provide any conclusive proof to demonstrate if a language may in fact have apodosis-protasis ordering in a conditional statement. However, to our knowledge, there is no record of any language in which the obligatory marking of two clauses is done through two overt and distinct markers. ${ }^{8}$ Nevertheless, closely related 
to this class, there is the case of the Ngiyambaa language in which the same marker is reported to be used in both clauses. In fact Comrie (1986: 84) cites the unique case of Ngiyambaa, observing that "in Ngiyambaa, with past tense counterfactuals, both clauses have the same overt marking (with the clitic -ma), and the first must be interpreted as protasis, ...”

(10) Nginuu-ma-ni burray giyi, ngindu-ma-ni yada gurawiyi

Lit. 'your-counterfactual-this child was, you-counterfactual-this well looked-after'

'If this child had been yours, you would have looked after it well.'9

It is not quite clear whether the so-called past tense counterfactual morpheme attested in the protasis and the apodosis in (10), viz. ma, does in fact mark both the protasis and the apodosis or if it performs different functions in different contexts, nor whether this phenomenon is limited to this type of conditional only or is attested in all other types of conditionals as well. However, the simple fact is that in Ngiyambaa, in the case of marking of two clauses through the same morpheme - no matter the purpose - the first clause is always considered the protasis, which clearly supports our hypothesis that there is indeed only protasis-apodosis ordering in natural languages.

\subsection{Class 2: Obligatorily marked $\mathrm{P}+$ Not-obligatorily marked $\mathrm{Q}$}

Now let us consider the second class, a class of languages in which according to traditional analyses only the protasis is believed to be marked obligatorily. The data from English, French and Italian, for example, seem to suggest an obligatory marking of the protasis (obtained through if, si and se, respectively) and an optional marking of the apodosis (obtained typically through some sort of proform, viz. then, alors and allora, respectively, which cannot appear sentence-initially). Although it is a topic of a separate study - thus outside the scope of this paper - whether the above mentioned proforms are in fact markers of the apodosis or of some other pragmatic elements, even a cursory examination of then reveals that English in reality has a null marker $[\varnothing]$ and uses then to express bi-conditional (i.e. if and only if) meanings, e.g. in (10)

(10) a. If you mow my lawn, I'll pay you ten dollars.

b. If you mow my lawn, then I'll pay you ten dollars. 
(10b) in fact means that ten dollars would be paid if, and only if, the lawn is mowed. Given that this purported English apodosis marker then carries a bi-conditionality meaning derived from the pragmatic scalarity in the protasis, a plausible explanation would be that it is associated with the protasis rather than with the apodosis. Then in fact is a pragmatic marker which induces implicatures, giving rise to bi-conditional readings, a topic that still requires much more serious investigation than it has received so far. Thus, to show the pragmatic affiliation of then with the protasis, we can roughly present (10) in the following manner:

(11) a. [If you mow my lawn, Ø] I'll pay you ten dollars. b. [[If you mow my lawn Ø] then] I'll pay you ten dollars.

where both (11a) and (11b) have a null marker and (11b) in addition has a pragmatic marker then which gives it if and only if reading. We can notice this meaning when we prepose the apodosis proposition. Thus, (11a) and (11b) can be rewritten as (12a) and (12b) respectively:

(12) a. I'll pay you ten dollars [if you mow my lawn Ø].

b. I'll pay you ten dollars [if, and only if, you mow my lawn Ø].

Therefore, according to our line of thinking, then is a pragmatic marker rather than an apodosis marker and pragmatically belongs to the protasis. Thus, it goes without saying that we do not regard (12a) and (12b) as cases of apodosis-protasis ordering. We consider that in these examples, the apodosis proposition - which was a part of the apodosis in a normal protasisapodosis ordering - has simply been preposed. We argue that then is a part of the conditional string, rather than of an apodosis and makes an anaphoric reference to the protasis. In order to marshal our argument, let us examine some other characteristics of then. Firstly, as Bhatt and Pancheva $(2006)^{11}$ have noted, then has to be adjacent to the protasis, as in (13a):

(13) a. If it rains, then I think that we should stay at home. b. ${ }^{*}$ If it rains, I think that then we should stay home.

In syntactic terms, it has been argued that the surface location of then marks a predicate that combines with the if-clause and therefore then must be structurally adjacent to the if-clause. However, the fact that then in such circumstances has to be adjacent to the protasis also proves that it is prag- 
matically associated with the protasis rather than with the apodosis as it has to pick out the scalarity from the protasis. Furthermore, then has a pragmatic role to play which is derived from the protasis and has no semantic role to play as far as its presumed affinity with the apodosis is concerned.

Secondly, there is a restriction on the use of then in those situations in which the protasis contains pragmatic elements expressing other pragmatic scales. In fact, being a pragmatic scalarity marker, then conflicts with other scalarity markers such as even if and only if, as is clear from examples (14) and (15):

(14) Even if it rains, *(then) the football game will happen.

(15) Only if it is sunny, *(then) I will visit you.

If we look at (14) and (15) carefully, it becomes evident that Bhatt and Pancheva's account of the above mentioned phenomenon does not seem to hold. It is not clear in the least, for example, what syntactic rules are presumed to preclude an appearance of then in (14) and (15) whose position is claimed to mark a predicate.

Likewise, there is yet another restriction on the use of then when it is employed in the so-called generic conditionals. Iatridou (1994) and Dancygier and Sweetser (1997), for instance, have variably argued ${ }^{12}$ that there is a restriction on the use of then when the protasis contains reference to generic time or event, as in (16):

(16) If Mary bakes a cake, *(then) she gives some slices of it to John.

where then anaphorically picks up a generic time reference from the protasis rather than from the apodosis and requires the apodosis to have the similar generic reference. The above mentioned characteristics of then clearly reveal its pragmatic nature and structural association with the protasis rather than with the apodosis. We can thus conclude that data from this class of languages do not provide convincing evidence to consider apodosisprotasis ordering valid.

\subsection{Class 3: Not obligatorily marked P + Obligatorily marked Q}

Now let us consider the class of languages in (9c) to which Hindi belongs. The strongest evidence against the purported apodosis-protasis ordering of 
clauses in conditional statements in fact comes from Hindi. ${ }^{13}$ The use of the so-called apodosis marker to (then) in Hindi is obligatory regardless of the presence or absence of the protasis marker agar (if), as can be seen in (17). It is attached to the protasis even when the apodosis has to dislocate in the apodosis-protasis ordering, as is attested in (18):

$$
\text { (agar) Rām } \bar{a} y \bar{a}, \quad \text { to } \tilde{m \varepsilon} u s-s e \quad p \bar{u} c h \tilde{\bar{u}} g \bar{a}
$$

(if) Ram come-PFV.M.SG then I he-ABL ask-FUT.M.1SG 'If Ram comes/came, I will/would ask him.'

$$
\begin{aligned}
& \tilde{m \varepsilon} \operatorname{Ra} m \text {-se pūch } \overline{\bar{u}} g \bar{a} \quad \text { agar vo } \bar{a} y \bar{a} \text { to } \\
& \text { I Ram-ABL ask-FUT.M.1SG if he come-PFV.M.SG then } \\
& \text { 'I will/would ask Ram if he comes/came.' }
\end{aligned}
$$

As mentioned above, in Hindi the apodosis marker to (then) has to remain attached to the protasis even when a conditional statement has to have the so-called apodosis-protasis clause ordering, as in (18). In fact an absence or a displacement of to (then) renders a Hindi conditional either ungrammatical or semantically odd, as can be noticed in (19a)-(19f):

$$
\begin{aligned}
& \text { a.*agar Rām } \bar{a} y \bar{a} \quad-m a \tilde{\imath} \text { us-se pūchīg } \bar{a} \\
& \text { if Ram come-PFV.M.SG - I he-ABL ask-FUT.M.1SG } \\
& \text { b. }{ }^{*}-R \bar{a} m \text { ayya } \quad-m a \tilde{\imath} \text { us-se pūchīg } \bar{a} \\
& \text { — Ram come-PFV.M.SG - I he-ABL ask-FUT.M.1SG }
\end{aligned}
$$

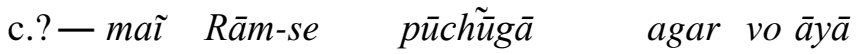

$$
\begin{aligned}
& \text { - I Ram-ABL ask-FUT.M.1sG if he come-PFV.M.SG } \\
& \text { d.*to maĩ Rām-se pūchīg } \bar{a} \text { agar vo } \bar{a} y \bar{a} \\
& \text { then I Ram-ABL ask-FUT.M.1SG if he come-PFV.M.SG }
\end{aligned}
$$

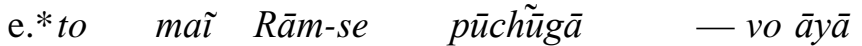

$$
\begin{aligned}
& \text { then I Ram-ABL ask-FUT.M.1SG - he come-PFV.M.SG }
\end{aligned}
$$

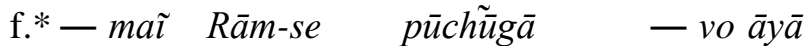

$$
\begin{aligned}
& \text { - I Ram-ABL ask-FUT.M.1SG — he come-PFV.M.SG } \\
& \text { 'I will/would ask Ram if he comes/ came.' }
\end{aligned}
$$

On the grammaticality test, the situation in the Hindi examples in (19) can be summarized as in (20) where $\alpha$ and $\beta$ are markers of the protasis and apodosis, respectively, $P$ and $Q$ the propositions contained in the protasis and the apodosis, and $\varnothing$, a null marker:

(20) a. $[\alpha P \rightarrow \varnothing Q]$ A grammatically unacceptable conditional string 
b. $[\varnothing P \rightarrow \varnothing Q]$ A grammatically unacceptable conditional string

c. $[\varnothing Q \leftarrow \alpha P] \quad$ A semantically unacceptable conditional string

d. $[\beta Q \leftarrow \alpha P] \quad$ A grammatically unacceptable conditional string

e. $[\beta Q \leftarrow \varnothing P]$ A grammatically unacceptable conditional string

f. [ØQ $\leftarrow \varnothing P]$ A grammatically unacceptable conditional string

Hindi conditionals require the particle to (then) to follow the protasis irrespective of the type of conditional (i.e. relevance or 'biscuit' ${ }^{14}$ conditionals (e.g. 21a and 21b), conditionals giving advice (e.g. 22a and 22b) or any other type of idiomatic conditional expressions (e.g. 23a and 23b).

a. (agar) $\bar{a} p$ cāhe to biskut àlmārī=mẽ

if you want-SUBJ.3PL then biscuits sideboard=in

rakhe $\tilde{h}$

placed aux-PRES.M.3PL

'If you want, there are biscuits on the sideboard.'

b. biskut ālmārī=me rakhe $\tilde{h} \bar{\varepsilon}$ agar biscuits sideboard=in placed aux-PRES.M.3PL if

ap cāhe to

you want-SUBJ.3PL then

'There are biscuits in the sideboard if you want them.'

(22)

a. (agar) āp merī bāt māne to koì

if you my advice accept-SUBJ.3PL then some

davā le lenā acchā hogā

medicine take better be-FUT.3SG

'If I were you, I would take some medicine.'

b. kō davā le lenā acchā hogāar agar

some medicine take better be-FUT.3SG if

$\bar{a} p$ merī bāt mānẽ to

you my advice accept-SUBJ.3PL then

'If I were you, I would take some medicine.'

(23) a. (agar) $\bar{a} p$ burā na mānẽ to ek bāt if you bad not consider-SUBJ.3PL then one thing

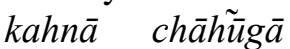

say want-FUT.3SG

'If you don’t mind, I would like to say something.' 


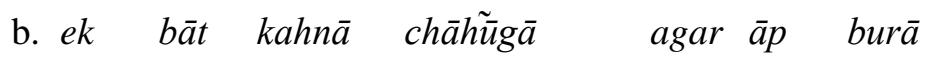

one thing tell want-FUT.3sG if you bad

na māne to

not consider-SUBJ.3PL then

'If you don't mind, I would like to say something.'

Moreover, in Hindi only the presumed apodosis marker to (i.e. then) carries all sorts of pragmatic meanings derived from scalarity (i.e. even if, only if, if and only if, etc.) in the protasis, as is clear from the examples in (24):

\begin{tabular}{|c|c|c|c|}
\hline a. (agar) & $\begin{array}{l}\text { unhõne } \\
\text { they-ERG }\end{array}$ & $\begin{array}{l}\text { mujhe } \\
\text { me }\end{array}$ & $\begin{array}{l}\text { bulāy } \bar{a} \\
\text { invite-PFV.M.SG }\end{array}$ \\
\hline$m \varepsilon$ & pārțī $=m \tilde{e}$ & $j \bar{a} \tilde{\bar{u}} g \bar{a}$ & \\
\hline I & party $=$ in & go-FUT.M. & \\
\hline
\end{tabular}
b. (agar) unhõne mujhe bulāya a $h \bar{\imath}$ if they-ERG me invite-PFV.M.SG then only $\tilde{m \varepsilon} \quad p \bar{a} r t \underline{\imath}=m \tilde{e} \quad j \bar{a} \bar{u} g \bar{a}$ I party=in go-FUT.M.1SG
'I will/would go to the party only if they invite/invited me.'
c. (agar) unhõne mujhe bulāyā to bhi if they-ERG me invite-PFV.M.SG then even

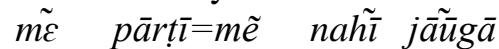 I party=in not go-FUT.M.1SG

'Even if they invite/invited me, I will/would not go to the party.'

All the examples in (24) unequivocally suggest a closer affinity of to (then) with the protasis rather than with the apodosis and provide proof that there is no apodosis-protasis ordering as such and that the conditionality of a sentence derives typically from the conditional string which includes the so-called apodosis marker as well.

\subsection{Class 4: Not obligatorily marked $\mathrm{P}+$ Not obligatorily marked $\mathrm{Q}$}

On the basis of different studies, Mandarin can be classified among those languages which seem to have characteristics described in category (9d), since in it "the protasis necessarily precedes the apodosis, whether the 
protasis alone is marked for non-factuality (by a conjunction such as rúguó 'if'), whether the apodosis alone is marked (for instance by nà and/or jìu 'then, in that case'), whether both are marked, or whether neither is marked.” (Comrie 1986: 85), as in

$\begin{array}{llllll}\text { (rúguǒ) Zhāngsān he jǔu, wǒ } & \text { (jìu) } & \text { mà } t \bar{a} \\ \text { (If) } & \text { Zhangsan drink wine I } & \text { (then) } & \text { scold him } \\ \text { 'If Zangsan drinks wine, (then) I will scold him.' } & \end{array}$
'If Zangsan drinks wine, (then) I will scold him.'

where, as Comerie points out, the protasis must precede the apodosis, irrespective of whether either protasis or apodosis is marked overtly. Needless to say, the case of Mandarin lends even stronger support to our hypothesis that there is only protasis-apodosis ordering in conditional statements regardless of the presence or absence of any overt clause markers.

We can sum up our discussion of above four possible classes exhibiting different possible orderings of two clauses in a conditional statement in table 1 .

Table 1. Table sumarizing the four classes of conditional statement. ${ }^{15}$

\begin{tabular}{lll}
\hline & $\mathrm{P} \rightarrow \mathrm{Q}$ & $\mathrm{Q}, \mathrm{P} \rightarrow$ \\
\hline 1. Class 1 & {$[\alpha \mathrm{P} \rightarrow \beta \mathrm{Q}]$} & - \\
2. Class 2 & {$[\alpha \mathrm{P} \rightarrow \emptyset(\beta) \mathrm{Q}]$} & {$[\mathrm{Q}[\alpha \mathrm{P} \rightarrow \varnothing]]$} \\
3. Class 3 & {$[(\alpha) \mathrm{P} \rightarrow \beta \mathrm{Q}]$} & {$[\mathrm{Q}[\alpha \mathrm{P} \rightarrow \beta]]$} \\
4. Class 4 & {$[(\alpha) \mathrm{P} \rightarrow(\beta) \mathrm{Q}]$} & - \\
\hline
\end{tabular}

As is clear from table 1, languages belonging to classes 2 and 3 seem to exhibit the so-called apodosis-protasis $(\mathrm{Q} \leftarrow \mathrm{P})$ ordering. In fact, data from these languages have led linguists to believe that a conditional statement may exhibit both clause orderings (i.e. $\mathrm{P} \rightarrow \mathrm{Q}$ and $\mathrm{Q} \leftarrow \mathrm{P}$ ). However, as we have argued above, these cases in no way violate the universal of conditional clause ordering (namely $\mathrm{P} \rightarrow \mathrm{Q}$ ), since in such cases only the proposition contained in the apodosis is preposed. A null-marker at the end of the conditional string in class 2 effectively indicates that in these languages a preposing of the apodosis-proposition does regularly take place as a result of speaker's different pragmatic strategies. Furthermore, data from the languages which belong to class 3 indubitably demonstrate that in these languages the so-called apodosis marker, say ' $\beta$ ', cannot be omitted and, except for a few cases, ${ }^{16}$ has to remain at the end of the conditional string even in cases where the apodosis-proposition has to be preposed or fronted. 
We believe that the preposing of apodosis-proposition attested in languages that belong to classes 2 and 3 of table 1 requires further pragmatic research in order to be better understood. One of the reasons of apodosisproposition preposing seems to derive from the fact that conditional statements are always discourse-bound (see e.g. Akatsuta 1986). In fact, the phenomenon of apodosis-proposition preposing, reduced conditionals (i.e. delition of either P or Q), nonconditional conditionals (see Lycan 2001 for details) and pseudo-conditionals can only be understood in the light of discourse-bound nature of conditional statements. Thus, we believe that depending on the elements of knowledge shared by the speaker and hearer (available from the previous part of the discourse) the speaker may consider it necessary to prepose the apodosis in order to highlight the information contained in it thus violating the normal clause-ordering. Another reason for apodosis-proposition preposing has to do with type of modality contained in it. In fact, when the speaker has to express deontic modality in making requests or orders he invaribly begins the conditional statement by preposing the apodosis-proposition, as in,

\section{(25) a. Sit down, if you want!}

b.? If you want sit down!

We believe that similar observations can be made about other conditional statements where the apodosis carries non-assertive illocutionary forces as is the case in uttering exclaimations, interrogatives etc. - and thus expresses a non-epistemic modality. Subject to further language specific research, we can expect apodoses carrying non-epistemic modal meanings to be always preposed - irrespective of syntactic differences in languages. In sum then, our analysis does not support the widely held belief according to which conditionals can have both orderings: $\mathrm{P} \rightarrow \mathrm{Q}$ and $\mathrm{Q} \leftarrow \mathrm{P}$.

\section{Do protases contain speaker's knowledge or beliefs?}

In order to determine an overall semantic contribution of the protasis to a conditional statement, it is necessary to establish the speaker's attitude towards the nonfactuality in the protasis. In other words, it is important to see whether the protasis can contain speaker's knowledge or beliefs. From the point of view of the speaker, conditional statements typically consist of three elements - the protasis, the apodosis and the relationship between the two - in which speaker's epistemic stand can be assessed. ${ }^{17}$ Now, if we 
look at the four traditional types of English conditionals, we notice that there are four different situations. In the first case, there is conditional type 0 such as If you heat water to 100 degrees celsius, it boils where the speaker knows the relation that holds between $P$ and $Q$, but neither knows nor believes the stae of affairs in $P$ and $Q$. In the case of second type of conditionals, such as If it rains this afternoon, everybody will stay home, the speaker neither knows nor believes the state of affairs in the protasis but believes in the relation that holds between $P$ and $Q$, and believes also that either necessarily or possibly $Q$ (i.e. everybody will stay home). In the third type of conditionals, such as If she came back early, he wouldn't be able to go to the party the speaker neither knows nor believes that $P$, but believes that possibly $Q$. The speaker believes that the relation between $P$ and $Q$ necessarily holds. The only category in which the speaker knows that 'necessarily not- $P$ ' is the fourth category. In fact, only the fourth type of conditionals, such as If she had bought a lottery ticket, she would have become rich contains the speaker's counter-to-fact knowledge, namely that 'she did not buy a ticket'. We can thus summarize the epistemic state of the speaker in four types of conditionals in the following table.

Table 2. Table showing the distribution of epistemic elements in the three parts of four types of epistemic conditional statements. ${ }^{18}$

\begin{tabular}{lcll}
\hline & $\mathrm{P}$ & $\rightarrow$ & $\mathrm{Q}$ \\
\hline 1. Conditional type 0 & $\neg \mathrm{K} P / \neg \mathrm{B} P$ & $\mathrm{~K}$ & $\neg \mathrm{KQ} / \neg \mathrm{B} Q$ \\
2. Conditional type 1 & $\neg \mathrm{K} P / \neg \mathrm{B} P$ & $\mathrm{~B}$ & $\mathrm{BQ}$ \\
3. Conditional type 2 & $\neg \mathrm{K} P / \neg \mathrm{B} P$ & $\mathrm{~B}$ & $\mathrm{BQ}$ \\
4. Conditional type 3 & $\mathrm{K} \neg P$ & $\mathrm{~K}$ & $\mathrm{~K} \neg Q / \mathrm{B} \neg Q$ \\
\hline
\end{tabular}

Thus, as explained above in epistemic conditionals protases do not contain speaker's knowledge or beliefs ${ }^{19}$ except in the fourth category of countefactuals where the speaker has a piece of counterfactual knowledge of the state of afairs in $P$ and $Q$. In the first category, the speaker does not possess any piece of knowledge regarding specific occurances of $P$ and $Q$, but rather of their generic occurances only. In other words, at all times, in all the cases of $P$ it is necessarily $Q$. As Comrie (1986: 88) has rightly observed, it is difficult to accept a neat biparttite or tripartite division of conditional statements with a clear-cut boundary between the two or three types. In fact, different degrees of hypotheticality in conditional statements are very much subjective. However, if we look at the speaker's epistemic state in table 2 we notice that there may be three types of conditionals only, as can 
be seen in table 3 where we have regrouped four types into three, namly A, $\mathrm{B}$ and $\mathrm{C}$. The conditional types 2 (namely If she gives me ten dollar, I will do her job) and 3 (namely If she gave me ten dollar, I would do her job) attested in languages such as English express exactly the same epistemic stand of the speaker, as is clear from table 3 . These three types can still be reduced to two types as the conditionals belonging to type 0 contain the lowest degree of hypotheticality and therefore are not real conditionals expressing hypotheticality. The conditionals in type 4 on the other hand contain the highest degree of hypotheticality.

Table 3. A regrouping of four types of conditional statements presented in table 2.

\begin{tabular}{lllll}
\hline & $\mathrm{P}$ & $\rightarrow$ & $\mathrm{Q}$ \\
\hline $\mathrm{A}$ & 1. Conditional type 0 & $\neg \mathrm{K} P / \neg \mathrm{B} P$ & $\mathrm{~K}$ & $\neg \mathrm{KQ} / \neg \mathrm{B} Q$ \\
$\mathrm{~B}$ & 2. Conditional type 1 & $\neg \mathrm{K} P / \neg \mathrm{B} P$ & $\mathrm{~B}$ & $\mathrm{BQ}$ \\
& 3. Conditional type 2 & $\neg \mathrm{K} P / \neg \mathrm{B} P$ & $\mathrm{~B}$ & $\mathrm{~B} Q$ \\
$\mathrm{C}$ & 4. Conditional type 3 & $\mathrm{K} \neg P$ & $\mathrm{~K}$ & $\mathrm{~K} \neg Q / \mathrm{B} \neg Q$ \\
\hline
\end{tabular}

Let us now take another issue which has a direct bearing on the role played by the protasis in a conditional statement. Syntactically, conditional clauses have generally been thought to belong to, thus considered to have similar qualities of, a class of adverbials or complementizers. For example, Bhatt and Pancheva (2006) synthesize a widespread common belief among linguists according to which the conditional clause belongs to a class of adverbial clauses that includes, among others, clausal adverbial of time, cause, and concessions, as can be seen in examples in (26).

(26) a. If Andrea arrived late, Clara must have got upset.

b. When Andrea arrived late, Clara got upset.

c. Because Andrea arrived late, Clara got upset.

d. Although Andrea arrived on time, Clara got upset.

It is argued that in (26a) the if-clause is attached to the then-clause in the same way as it is in the rest of examples (i.e. 26b, 26c, 26d). Thus, according to this line of research, the conditional clause should get a treatment similar to the one in other cases. In pragmatic terms, though, this idea does not seem to stand up to close scrutiny. In our view, one of the striking characteristics of the protasis is that it, unlike other syntactic complementizers, does not carry and thus does not attach (or contribute) to conditional statements any epistemic elements derived from speaker's knowledge or beliefs. To see the epistemic state of examples in (26) we can rephrase 
them in (27). We claim that, contrary to the widely held belief, protases do not carry speaker's knowledge or belief, as can be seen in (27a) where the speaker neither knows nor believes that Andrea in fact came late at time $t$ and thus the speaker's necessary belief (B):

(27) a. ?The speaker knows that 'Andrea arrived late at time $t$ ', and the speaker believes that 'Clara got upset at time $t$ '.

b. The speaker knows that (i) 'Andrea arrived late at time $t$ ', and (ii) 'Clara got upset at time $t$ '.

c. The speaker knows that (i) 'Andrea arrived late at time t', and (ii) 'Clara got upset at time $t$ ' and believes that '(i) caused (ii)'.

d. The speaker knows that (i) 'Andrea arrived on time at time $t$ ', and (ii) 'Clara got upset at time $t$ '. The speaker believes that '(ii) took place notwithstanding (i)'

In fact, (26a) cannot be paraphrased as (27a) since the speaker in making an utterance of (26a) does not know that Andrea in fact arrived late. Had the speaker known that, he would have instead made an utterance using other constructions such as: Given that/Since/ As/ For Andrea arrived late ... Consequently, we believe that it is a fundamental mistake to equate a conditional clause with an adverbial complementizer. There are no proofs to support the idea that (26a) is semantically similar to (26b), (26c) and (26d).

Let us consider another similar argument which is related to the question of the presence or absence of speaker's epistemic elements, namely knowledge and beliefs in the protasis. In various syntactic analyses, it has been observed that conditional clauses (i.e. protases) are incompatible with Main Clause Phenomenon (exemplified in English by argument fronting). For example, it has been argued that English does not permit argument fronting, as (28b) is ungrammatical:

(28) a. If you don't pass these exams, you won't get the degree. b. 'If these exams you don't pass, you won't get the degree.

Similarily, the protasis cannot contain the so-called Speaker Oriented Adverbs. For example, an adverb such as frankly, renders (29b) ungrammatical.

(29) a. If he's unable to cope, we'll have to replace him.

b. ??*If frankly he's unable to cope, we'll have to replace him. 
We believe that these syntactic phenomena have to be considered from the point of view of the speaker's epistemic stand only since it is difficult to provide an elegant syntactic analysis of conditionals without taking into consideration modal meanings of the speaker.

\section{The distribution of TAM elements in the Hindi protasis}

The TAM elements in the protasis are responsible for establishing different degrees of hypotheticality in a conditional statement as a whole, although they do not indicate the same meanings as they do when used in factual propositions. In order to show the distribution of Hindi TAM elements, we provide a list of possible combinations of the protasis and the apodosis in Hindi conditional statements in Appendix 3.

Table 4. Distribution of possible TAM elements in the protasis and the apodosis of the Hindi conditional statements. ${ }^{20}$

\begin{tabular}{llll}
\hline & & P & Q \\
\hline 1. & Simple perfective (aorist) & YES & YES \\
2. & Past (aspect-less) & YES & YES \\
3. & Past habitual & YES & YES \\
4. & Past progressive & YES & YES \\
5. & Past perfective & YES & YES \\
6. & Present (aspect-less) & YES & YES \\
7. & Present habitual & YES & YES \\
8. & Present progressive & YES & YES \\
9. & Present perfective & YES & YES \\
10. & Future (aspect-less, presumptive) & YES & YES \\
11. & Future habitual (presumptive) & YES & YES \\
12. & Future progressive (presumptive) & YES & YES \\
13. & Future perfective (presumptive) & YES & YES \\
14. & Subjunctive (aspect-less) & YES & YES \\
15. & Subjunctive habitual & YES & YES \\
16. & Subjunctive progressive & YES & YES \\
17. & Subjunctive perfective & YES & YES \\
18. & Counterfactual (aspect-less) & YES & YES \\
19. & Counterfactual habitual & YES \\
20. & Counterfactual progressive & YES \\
21. & Counterfactual perfective & YES & YES \\
22. & Imperatives & YES & YES \\
23. & Interrogatives & NO & YES \\
& & NO & YES
\end{tabular}


As can be seen in more detail in Appendix 3, in Hindi the conditional type 0 employs the present habitual in $\mathrm{P}$ and $\mathrm{Q}$ whereas the conditional type 3 necessarily employs TAM elements listed in 18, 19, 20, 21 in table 4. The conditional type 2 requires $P$ to be in the aorist tense and $Q$ in the future tense. The conditional type 1 makes use of the rest of Hindi TAM elements.

\section{Conclusions}

Analyzing data mainly from Hindi, we have shown that a conditional statement obligatorily contains - either overtly or covertly - a conditional string, namely $\mathrm{P}-\mathrm{Q}$, which is indivisible and that the order of the two elements in the conditional string can never be reversed. This conclusion will have important implications for any type of syntactic analysis which aims to provide a division of a conditional statement according to the traditional line of thinking, namely $[[\mathrm{P}-],[\mathrm{Q}-]]$. Our proposal in this regard is that a syntactic analysis of conditional statements should have the following form: $[[\mathrm{P}-, \mathrm{Q}]-]]$ and, with a possible alternation, $[-[\mathrm{P}-, \mathrm{Q}]]$, due to the preposing of the proposition contained in the apodosis. Thus we reject the syntactic analyses which look at the phenomenon along these lines: $[[\mathrm{Q}-],[\mathrm{P}-]]$. We have also demonstrated that the Hindi TAM elements in the protasis set up different degrees of hypotheticality of a conditional statement. In addition, we have shown that contrary to widely held belief, the protasis carries neither speaker knowledge nor speaker belief. This pragmatic fact also explains why the protasis can contain neither the fronted argument nor speaker-oriented adverbs.

\section{Appendix 1}

To see the distribution of the Hindi TAM elements in the protasis (i.e. P), we provide in this appendix a list of examples which contain 21 out of 24 categories we registered in Table 3. Needless to say, imperatives, interrogatives and exclamations cannot appear in the protasis.

P-TAM-1 Simple perfective/ aorist agar/us-ne/ un dinõ/vakālat/ kī/ to ... 
if/ he-ERG/ those days/ advocacy-F/ do-PFV.F.3SG/ then ...

'If he practiced law those days, then ...'

P-TAM-2 Past (aspect-less)

agar/vo/ un dinõ/ vakill/ thä/ to ...

if/ he/ those days/ lawyer/ be-PST.M.3sG/ then ...

'If he was a lawyer those days, then ...'

P-TAM-3 Past habitual

agar/vo/ un dinõ/vakālat/ kartā/ thä/ to ...

if/ he/ those days/ advocacy-F/ do-IMPFV.M.3SG/ AUX-PST.M.3SG/ then ...

'If he practiced/ would practice law those days then ...'

P-TAM-4 Past progressive/

agar/vo/ us samay/vakālat/ kar rahä/ thā/ to ...

if/ he/ that period/ advocacy-F/ do-PROG.M.3SG/ AUX-PST.M.3SG/ then ...

'If he was practicing law during that period, then ...'

P-TAM-5 Past perfective

agar/ us-ne/ us samay/vakālat/ kī/ thì/ to ...

if/ he-ERG/ at that time/ advocacy-F/ do-PFV.F.3sG/ AUX-PST.F.3SG/ then ...

'If he then had practiced law, then ...'

P-TAM-6 Present (aspect-less)

agar/vo/ vakil/ he/ to ...

if/ he/ lawyer/ be-PREs.3sg/ then ...

'If he is a lawyer, then ...'

P-TAM-7 Present habitual

agar/vo/ ab/vakālat/ kartā/ he/ to ...

if/ he/ now/ advocacy-F/ do-IMPFV.M.3SG/ AUX-PRES.3SG/ then ...

'If he practices law now, then ...'

P-TAM-8 Present progressive agar/vo/ ab/vakālat/ kar rahā/ he/ to ...

if/ he/ now/ advocacy-F/ do-PROG.M.3SG/ AUX-PRES.3SG/ then ...

'If he is practicing law now, then ...'

P-TAM-9 Present perfective

agar/ us-ne/vakālat/ kī/ he/ to ...

if/ he-ERG/ advocacy-F/ do-PFV.F.3SG/ AUX-PRES.3SG/ then ...

'If has practiced law, then ...'

P-TAM-10 Future (aspect-less)

agar/vo/vakālat/ karegā/ to ...

if/ he/ advocacy-F/ do-M.3sG/ then ...

'If he will practice law, then ...'

P-TAM-11 Future habitual (presumptive habitual)

agar/vo/vakālat/ kartā/ hogāal to ... 
if/ he/ advocacy-F/ do-IMPFV.M.3SG/ AUX-PRESM/ then ... 'If he must be practicing law, then ...'

P-TAM-12 Future progressive (presumptive progressive) agar/vo/vakālat/ kar rahä/ hogä/ to ...

if/ he/ advocacy-F/ do-PROG.M.3sG/ AUX-FUT.M.3sG/ then ...

'If he must be practicing law, then ...'

P-TAM-13 Future perfective (presumptive perfective)

agar/us-ne/vakālat/ kī/ hogī/ to ...

if/ he-ERG/ advocacy-F/ do-PFV.F.3SG/ AUX-FUT.F.3SG/ then ...

'If he must have practiced law, then ...'

P-TAM-14 Subjunctive (aspect-less)

agar/vo/vakälat/ kare/ to ...

if/ he/ advocacy/ do-SUBJ.3sg/ then ...

'If he should practice law, then ...'

P-TAM-15 Subjunctive habitual

agar/vo/ vakälat/ kartā/ ho/ to ...

if/ he/ advocacy-F/ do-IMPFV.M.3SG/ AUX-SUBJ/ then ...

'If he may be practicing law, then ...'

P-TAM-16 Subjunctive progressive agar/vo/ vakālat/ kar rahä/ ho/ to ...

if/ he/ advocacy-F/ do-PROG.M.3sG/ AUX-SUBJ.3SG/ then ...

'If he may be practicing law, then ...'

P-TAM-17 Subjunctive perfective agar/ us-ne/vakālat/ kī/ ho/ to ...

if/ he-ERG/ advocacy-F/ do-PFV.F.3SG/ AUX-SUBJ.3SG/ then ...

'If he may have practiced law, then ...'

P-TAM-18 Counterfactual (aspect-less)

agar/vo/vakālat/ kartä/ to ...

if/ he/ advocacy-F/ do-IMPFV.M.3sG/ then ...

'If he had practiced law then ...'

P-TAM-19 Counterfactual habitual

agar/ vo/ un dinõ/vakālat/ kartā/ hotā/ to ...

if/ he/ those days/ advocacy-F/ do-IMPFV.M.3sG/ AUX-IMPFV.M.3sG/ then ...

'If he had been practicing law those days, then ...'

P-TAM-20 Counterfactual progressive

agar/vo/ un dinõ/vakālat/ kar rahā/ hotā/ to ...

if/ he/ those days/ advocacy-F/ do-PROG.M.3sG/ AUX-IMPFV.M.3sG/ then ...

'If he had been practicing law those days, then ...'

P-TAM-21 Counterfactual perfective

agar/ us-ne/ vakälat/ kī/ hotì/ to ... 
if/ he-ERG/ advocacy-F/ do-PFV.F.3SG/ AUX-IMPFV.F.3SG/ then ...

'If he had practiced law, then ...'

\section{Appendix 2}

In this appendix, we provide examples of the apodosis (i.e. Q) containing all the 24 types of TAM elements listed in Table 3.

Q-TAM-1 Simple perfective (aorist)

(to)/ usne/ zarūr/ ferrārī/ kharìd

(then)/ he-ERG/ certainly/ Ferrari/ buy-PFV.F.3SG

'(then) he certainly bought a Ferrari.'

Q-TAM-2 Past (aspect-less)

(to)/ vo/ bahut pese vālā/ thā

(then)/ he/ very rich/ be-PST.M.3sG

'(then) he was very rich.'

Q-TAM-3 Past habitual

(to)/ vo/ roz/ wiskì pītāa thā

(then)/ he/ everyday/ whisky/ drink-IMPFV.M.SG/ AUX-PST.M.3SG

'(then) he drank whisky everyday.'

Q-TAM-4 Past progressive

(to)/vo/ us samay/ wiskì/ pī rahä/ thā

(then)/ he/ at that moment/ whisky/ drink-PROG.M/ AUX-PST.M.3SG

'(then) he was drinking whisky at that moment.'

Q-TAM-5 Past perfective

(to)/ usne/ zarūr/ ferrārī//kharīd lī/ thī

(then)/ he-ERG/ certainly/ Ferrari/ buy-take-PFV.F.SG/ AUX-PREs.3SG

'(then) he certainly had bought a Ferrari.'

Q-TAM-6 Present (aspect-less)

(to)/ vo/ bahut pese vālä/ he

(then)/ he/ very rich/ be-PRES.3SG

'(then) he is very rich.'

Q-TAM-7 Present habitual

(to)/ vo/ roz/ wiskī/pìtā/ he

(then)/ he/ everyday/ whisky/ drink-IMPFV.M.SG/ AUX-PRES.3SG

'(then) he drinks whisky everday.'

Q-TAM-8 Present progressive

(to)/vo/ is samay/ wiskī/pī rahä/ he

(then)/ he/ this moment/ whisky/ drink-PROG.M.SG/ AUX-PRES.3SG

'(then) he is drinking whisky at the moment.' 
Q-TAM-9 Present perfective (to)/ usne/ zarūr/ ferrārī/ kharīd lī/ he

(then)/ he-ERG/ certainly/ Ferrari/ buy-take-PFV.F.SG/ AUX-PRES.3sG

'(then) he certainly has bought a Ferrari.'

Q-TAM-10 Future (aspect-less, presumptive)

(to)/vo/ zarūr/ bahut pese vālä/ hogā

(then)/ he/ certainly/ very rich/ be-FUT.3sG

'(then) he must certainly be very rich.'

Q-TAM-11 Future habitual (presumptive)

(to)/vo/ zarūr/ roz/wiskī/ pìtā/ hog $\bar{a}$

(then)/ he/ certainly/ everyday/ whisky/ drink-IMPFV.M.SG/ AUX-PRES.3SG

'(then) he must be drinking whisky everyday.'

Q-TAM-12 Future progressive (presumptive)

(to)/vo/zarūr/ is samay/wiskī/pī rahä/ hogā

(then)/ he/ certainly/ this moment/ whisky/ drink-PROG.M.SG/ AUX-PRES.3SG

'(then) he must be drinking whisky at the moment.'

Q-TAM-13 Future prefective (Presumptive)

(to)/ usne/ zarūr/ ferrārī/ kharīd lìl/hogī

(then)/ he-ERG/ certainly/ Ferrari/ buy-take-PFV.F.SG/ AUX-FUT.F.3sG

'(then) he certainly must have bought a Ferrari.'

Q-TAM-14 Subjunctive (aspect-less)

(to)/ ho saktā he ki/vo/bahut pese vālä/ ho

(then)/ it may be that/ he/ very rich/ be-SUBJ.3SG

'(then) maybe he is very rich.'

Q-TAM-15 Subjunctive habitual

(to)/ ho saktā he ki/vo/ roz/wiskī/ pītä/ ho

(then)/ may be that/ he/ everyday/ whisky/ drink-IMPFV.M.SG/ AUX-SUBJ.3SG

'(then) it may be that he drinks whisky everyday.'

Q-TAM-16 Subjunctive progressive

(to)/ ho saktā he ki/vo/ ab/wiskī/pī rahä/ ho

(then)/ may be that/ he/ now/ whisky/ drink-PROG.M.SG/ AUX-SUBJ.3SG

'(then) he may be drinking whisky now.'

Q-TAM-17 Subjunctive perfective

(to)/ ho saktā he ki/ usnel ferrārī/ kharīd lī/ ho

(then)/ may be that/ he-ERG/ Ferrari/ buy-take-PFV.F.SG/ AUX-SUBJ.3SG

'(then) he may have bought a Ferrari.'

Q-TAM-18 Counterfactual (aspect-less)

(to)/vo/ bahut pese vālā/ hotā

(then)/ he/ very rich/ be-IMPFV.M.3SG

'(then) he would have been very rich.' 
Q-TAM-19 Counterfactual habitual

(to) $/ \mathrm{vo} / \mathrm{roz} / \mathrm{wisk} \bar{l} / \mathrm{p} \bar{t} t \bar{a} /$ hotā

(then)/ he/ everyday/ whisky/ drink-IMPFV.M.SG/ AUX-IMPFV.M.3SG

'(then) he would have been drinking whisky everyday.'

Q-TAM-20 Counterfactual progressive

(to)/vo/ is samay/ wiskī/p $\bar{\imath}$ rahā/ hotā

(then)/ he/ this moment/ whisky/ drink-PROG.M.SG/ AUX-IMPFV.M.3SG

'(then) he would have been drinking whisky now.'

Q-TAM-21 Counterfactual perfective

(to)/ usne/ zarūr/ferrārī/ kharīd lī/ hotī

(then)/ he-ERG/ certainly/ Ferrari/ buy-take-PFV.F.SG/ AUX-IMPFV.F.3SG

'(then) he certainly would have bought a Ferrari.'

Q-TAM-22 Imperative

(to)/ use/ zarūr/ bulāo

(then)/ him/ certainly/ invite-IMP.2PL

'(then) invite him!'

Q-TAM-23 Interrogative

(to)/ uskā/ bețā/kyā/kartā/h $\varepsilon$

(then)/ his/ son/ what/ do-IMPFV.M.3SG/ AUX-PRES.3SG

'(then) what does his son do?'

Q-TAM-24 Exclamations

(to)/mujhe/ kyā/lenā-denā!

(then)/ to me/ what/ take-give

'(then) who cares!'

\section{Appendix 3}

In this appendix we provide a list of possible combinations of different types of protasis $(\mathrm{P})$ and apodosis $(\mathrm{Q})$ in conditional statements in Hindi. All the numbers refer to those in Table 3. Although the list is derived bearing in mind a possible combination of types in Appendix 1 and Appendix 2, not all the following combinations can be obtained by simply combining the examples we have supplied since their semantic content is not always coherent.

P-TAM-1 + [Q-TAM-2]/ [Q-TAM-6]/ [Q-TAM-10]/ [Q-TAM-11]/ [Q-TAM-12]/ [QTAM-13]/ [Q-TAM-14]/ [Q-TAM-15]/ [Q-TAM-16]/ [Q-TAM-17]/ [QTAM-22]/ [Q-TAM-23]/ [Q-TAM-24] 
P-TAM-2 + [Q-TAM-2]/[Q-TAM-3]/ [Q-TAM-10]/ [Q-TAM-11]/ [Q-TAM-12]/ [QTAM-13]/ [Q-TAM-14]/ [Q-TAM-15]/ [Q-TAM-16]/ [Q-TAM-17]/ [QTAM-22]/ [Q-TAM-23]/ [Q-TAM-24]

P-TAM-3 + [Q-TAM-2]/ [Q-TAM-10]/ [Q-TAM-11]/ [Q-TAM-12]/ [Q-TAM-13]/ [QTAM-14]/ [Q-TAM-15]/ [Q-TAM-16]/ [Q-TAM-17]/ [Q-TAM-22]/ [QTAM-23]/ [Q-TAM-24]

P-TAM-4 + [Q-TAM-2]/ [Q-TAM-10]/ [Q-TAM-11]/ [Q-TAM-12]/ [Q-TAM-13]/ [QTAM-14]/ [Q-TAM-15]/ [Q-TAM-16]/ [Q-TAM-17]/ [Q-TAM-22]/ [QTAM-23]/ [Q-TAM-24]

P-TAM-5 + [Q-TAM-2]/[Q-TAM-6]/ [Q-TAM-10]/ [Q-TAM-11]/ [Q-TAM-12]/ [QTAM-13]/ [Q-TAM-14]/ [Q-TAM-15]/ [Q-TAM-16]/ [Q-TAM-17]/ [QTAM-22]/ [Q-TAM-23]/ [Q-TAM-24]

P-TAM-6 + [Q-TAM-6]/ [Q-TAM-7]/ [Q-TAM-8]/ [Q-TAM-9]/ [Q-TAM-10]/ [Q-TAM11]/ [Q-TAM-12]/ [Q-TAM-13]/ [Q-TAM-14]/ [Q-TAM-15]/ [Q-TAM-16]/ [Q-TAM-17]/ [Q-TAM-22]/ [Q-TAM-23]/ [Q-TAM-24]

P-TAM-7 + [Q-TAM-6]/ [Q-TAM-7]/ [Q-TAM-8]/ [Q-TAM-9]/ [Q-TAM-10]/ [Q-TAM11]/ [Q-TAM-12]/ [Q-TAM-13]/ [Q-TAM-14]/ [Q-TAM-15]/ [Q-TAM-16]/ [Q-TAM-17]/ [Q-TAM-22]/ [Q-TAM-23]/ [Q-TAM-24]

P-TAM-8 + [Q-TAM-6]/ [Q-TAM-7]/ [Q-TAM-8]/ [Q-TAM-9]/ [Q-TAM-10]/ [Q-TAM11]/ [Q-TAM-12]/ [Q-TAM-13]/ [Q-TAM-14]/ [Q-TAM-15]/ [Q-TAM-16]/ [Q-TAM-17]/ [Q-TAM-22]/ [Q-TAM-23]/ [Q-TAM-24]

P-TAM-9 + [Q-TAM-6]/ [Q-TAM-7]/ [Q-TAM-8]/ [Q-TAM-9]/ [Q-TAM-10]/ [Q-TAM11]/ [Q-TAM-12]/ [Q-TAM-13]/ [Q-TAM-14]/ [Q-TAM-15]/ [Q-TAM-16]/ [Q-TAM-17]/ [Q-TAM-22]/ [Q-TAM-23]/ [Q-TAM-24]

P-TAM-10 + [Q-TAM-10]/[Q-TAM-12]/ [Q-TAM-13]/ [Q-TAM-22]/ [Q-TAM-23]/ [QTAM-24]

P-TAM-11 + [Q-TAM-22]/ [Q-TAM-23]/ [Q-TAM-24]

P-TAM-12 + [Q-TAM-10]/ [Q-TAM-11]/ [Q-TAM-12]/ [Q-TAM-13]/ [Q-TAM-22]/ [QTAM-23]/ [Q-TAM-24]

P-TAM-13 + [Q-TAM-10]/ [Q-TAM-11]/ [Q-TAM-12]/ [Q-TAM-13]/ [Q-TAM-14]/ [QTAM-22]/ [Q-TAM-23]/ [Q-TAM-24]

P-TAM-14 + [Q-TAM-14]/ [Q-TAM-22]/ [Q-TAM-23]/ [Q-TAM-24]

P-TAM-15 + [Q-TAM-10]/[Q-TAM-14]/ [Q-TAM-15]/ [Q-TAM-16]/ [Q-TAM-17]/ [QTAM-22]/ [Q-TAM-23]/ [Q-TAM-24]

P-TAM-16 + [Q-TAM-14]/ [Q-TAM-15]/ [Q-TAM-16]/ [Q-TAM-17]/ [Q-TAM-22]/ [QTAM-23]/ [Q-TAM-24]

P-TAM-17 + [Q-TAM-6]/[Q-TAM-10]/[Q-TAM-14]// [Q-TAM-15]/ [Q-TAM-16]/ [QTAM-17]/ [Q-TAM-22]/ [Q-TAM-23]/ [Q-TAM-24]

P-TAM-18 + [Q-TAM-18]/ [Q-TAM-19]/ [Q-TAM-20]/ [Q-TAM-21]/ [Q-TAM-22]/ [QTAM-23]/ [Q-TAM-24]

P-TAM-19 + [Q-TAM-18]/ [Q-TAM-19]/ [Q-TAM-20]/ [Q-TAM-21]/ [Q-TAM-22]/ [QTAM-23]/ [Q-TAM-24] 


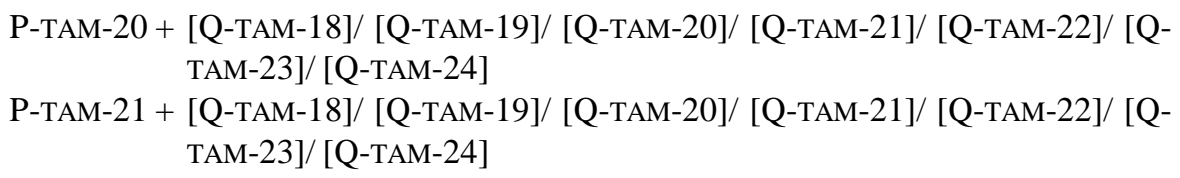

\begin{abstract}
Abbreviations
1 = first person; 2 = second person; 3 = third person; $\mathrm{ABL}=$ ablative; $\mathrm{ACC}=$ accusative; $\mathrm{AUX}=$ auxiliary; $\mathrm{CFV}=$ contrafactive $($ counterfactual); $\mathrm{CONT}=$ continuous; ERG = ergative; $\mathrm{F}=$ feminine; FUT $=$ future; $\mathrm{HON}=$ honorific; $\mathrm{IMP}=$ imperative; IMPFV = imperfective; $\mathrm{M}=$ masculine; $\mathrm{OBL}=$ oblique; PART = particle; PASS = passive; $\mathrm{PFV}=$ perfective; $\mathrm{PL}=$ plural; PRES $=$ present PRESM = presumptive; PROG = progressive; $\mathrm{PST}=$ past; $\mathrm{SG}=$ singular; $\mathrm{SUBJ}=$ subjunctive .
\end{abstract}

\title{
Notes
}

* I am grateful to Professor Peter Edwin Hook (Michigan) for helpful suggestions. Needless to say, I am solely responsible for all errors and inaccuracies which may occur.

1. Although familiar with the technicalities of different brands of theories of conditionals, both formal and informal, semantic as well as syntactic, we intend to avoid any direct discussion of them altogether since our aim in this brief study is to put forward certain new ideas and our conviction is that once one starts discussing the technicalities of any theory, one remains entrapped in it, in a no-go situation. This is especially when, in order to follow these theories, you have to begin by using the terms which have been inappropriately used for centuries. Most of the logical theories of conditionals, to cite just one case, have misused the terms 'indicative' and 'subjunctive' in their discussion, without ascertaining the basic meaning of the terms. Thus, we will be using the following terms and symbols: protasis $=$ the first clause or P-clause or the antecedent, apodosis $=$ the second clause or Q-clause or consequent, $\square=$ modal necessity operator, $\diamond=$ modal possibility operator, $\neg=$ negative modality operator.

2. After giving a concise account of different syntactic theories of conditional, Bhat and Pancheva (2006) advance an idea by which there is a need to provide two different solutions for two types of attachments, one for the sentenceinitial protasis and another for the sentence-final protasis. We believe that syn- 
tacticians will rather have to find some other solutions for a dislocation of the proposition contained in the apodosis.

3. A good discussion of such quasi-conditionals in English can be found in "Non-conditional Conditionals", Michael L. Geis and William G. Lycan in Real Conditionals W. G. Lycan, Oxford: Clarendon Press, pp. 184-205.

4. For an excellent survey of such pseudo-P or pseudo-Q conditional constructions, see Renaat Declerck and Susan Reed (2001).

5. Without paying due attention to the crucial role played by the protasis (conditional clause) in the actualization of a conditional statement, most studies have by and large accepted the terms 'subordinate clause' or 'dependent clause' to designate the protasis. We argue that this is misleading since the protasis is the founding clause of a conditional statement and thus cannot be termed 'dependent'. Citing the Cambridge International Dictionary of English, Declerck and Reed (2001) argue that a 'subordinate' clause is the one which cannot form a separate sentence but which can form a sentence when joined with a main clause. In the present study we do not follow this line of thought.

6. See Johnson-Laird 1986.

7. Elisabeth Traugott, Alice Ter Meulen, Juddy Snitzer Reilly, and Charles A. Ferguson, 1986, p. 9.

8. As mentioned in Sharma (2010), our claim is based exclusively on the data discussed in the following typological studies: (1) Typology of Conditional Constrctions, Victor S. Xrakovskij (ed.), (2005) for Bulgarian (Rousselina Nicolova), Armenian (Natalia A. Kozintseva), Dari (Boris Ya. Ostrovsky), Hindi (Tatayana I. Oranskaya), Homeric Greek (Ilja A. Perelmouter), Early Latin (Margarita K. Sabaneyeva), French (Elena E. Kordi), German (Svetlana M. Kibardina), English (Tatiana G. Akimova, Natalia A. Kozintseva), Finnish (Hannu Tommola), Estonian (Irina P. Külmoja), Hungarian (László Jaszai, Ethelka Tóth), Hausa (Myrrah A. Smirnova, Nikolaj A. Dobronravin), Klamath (Viktor A. Stegniy), Indonesian (Alexander K. Ogloblin), Cambodian (Natalia M. Spatari), Vietnamese (Igor S. Bystrov, Nonna V. Stankevič), Chinese (Tamara N. Nikitina), Even (Andrej L. Malchukov), Evenki (Igor V. Nedjalkov, Nina Ya. Bulatova), Eskimo (Nikolaj B. Vaxtin), Aleut (Evgeniy V. Golovko), Yukaghir languages (Elena S. Maslova) and Japanese (Vladimir M. Alpatov, Vera I. Podlesskaya); (2) The semantics of Clause Linking, R. M. W. Dixon, and Alexandra Y. Aikhenvald (eds.), (2009) for Akkadian, Galo, Khan, Manambu, Iquito, Aguaruna, Ojibwe, Fijian, Toqabaqita, Martuthunira, Korean, Goemai, Konso and Mali; (3) The Indo-Aryan Languages, Colin P. Masica, (1991) for various Indo-Aryan languages. None of the languages discussed in above mentioned works seems to have 'apodosis-protasis' ordering with overt markers.

9. Donaldson (1980: 251-2), cited in Comrie (1986: 84).

10. In logic, conditionals (i.e. material implications: $\mathrm{P} \rightarrow \mathrm{Q}$ ) are defined as a relation between $\mathrm{P}$ and $\mathrm{Q}$ which is said to be true in the following three cases: (1) 
$\mathrm{P}$ and $\mathrm{Q}$ are true (2) $\mathrm{P}$ is false and $\mathrm{Q}$ is true (3) both $\mathrm{P}$ and $\mathrm{Q}$ are false. The relation is false only when $\mathrm{P}$ is true and $\mathrm{Q}$ is false. In bi-conditionality $(\mathrm{P} \leftrightarrow \mathrm{Q})$, the relation is false in the second case: $\mathrm{P}$ is false and $\mathrm{Q}$ is true. Geis and Zwicky (1971) were perhaps the first to notice this and to claim that the actual interpretation of many conditional sentences is a bi-conditional ('if and only if') interpretation. Thus, If it rains, they will cancel the game (P, Q) is taken to mean No rain, no cancellation $(\neg \mathrm{P}, \neg \mathrm{Q})$. Likewise, Iatridou $(1991,1994)$ argues that the use of then in a conditional statement suggests that an iff-reading is not false.

11. Bhatt and Pancheva (2006) cite these examples from R. Izvorski, The Present Perfect as an Epistemic Modal. In A. Lawson (ed.) Proceedings of SALT VII, Cornell University, Ithaca, NY, Cornell Linguistic Club, 1997.

12. According to Iatridou $(1991,1994)$ then in conditional statements is not vacuous and is associated with a particular presupposition. A conditional of the form 'If $\mathrm{P}$, then $\mathrm{Q}$ ' presupposes that some of the $\neg \mathrm{P}$ are $\neg \mathrm{Q}$.

13. We assume that further supportive evidence may come form other Indo-Aryan languages, although we have made no attempt in this direction.

14. Named so after Austin's famous example, "If you are hungry, there are biscuits on the sideboard." (Austin 1961)

15. In this table, $\mathrm{P}$ and $\mathrm{Q}$ stand for the propositions contained in the protasis and the apodosis respectively. $\alpha$ and $\beta$ are overt markers of the protasis and the apodosis respectively. The element within brackets () is not-obligatory. $\varnothing$ is a null marker.

16. As mentioned above, Hindi conditionals require the so-called apodosis marker to 'then' to be used always, no matter what the cluase ordering is (i.e. $[$ agar $\mathrm{P} \rightarrow$ to $\mathrm{Q}]$ or [Q-[agar-P $\rightarrow$ to]]). Nevetheless, it is possible to encounter examples such as the following one where the use of to in [Q-[agar-P $\rightarrow$ to]] is not obligatory:

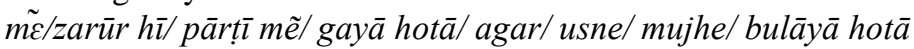

I/ certainly EMP/ party=in/ go-PFV-M-SG aux-IMFV-M-SG/if/ he-ERG/ invite-PFVM-SG aux-IMFV-SG

'I certainly would have gone to the party if he/she had invited me.'

17. In this discussion we are concerned exclusively with the protases which contain some epistemic elements. Thus, we do not attempt to analyze conditional statements such as "If you open the window, I will kiss/kill you" where the protasis carries the speaker's indirect illocutions, invitation/prohibition to carry out the task rather than speaker's epistemic stand.

18. As in the table 1, P and Q stand for propositions of the protasis and the apodosis respectively. K and B stand for 'knowledge' and 'belief' and $\neg$ is a negative marker. The arrow indicates the relationship between $\mathrm{P}$ and $\mathrm{Q}$.

19. We do not consider example such as If you love Clara so much, why don't you marry her a counter-example even if in such cases the speaker may know the 
facts reported in the protasis since it is the speaker's epistemic comunicative stand that counts not what he may know or believe.

20. Examples for P-clause and Q-clause are provided in the Appendices 1 and 2, respectively.

\section{References}

Akatsuka, Noriko

1986 Conditionals are discourse-bound. In On Conditionals, Elizabeth Closs Traugott, Alice ter Meulen, Judy Snitzer Reilly, and Charles A. Ferguson (eds.), 333-351. Cambridge: Cambridge University Press.

Austin, John L.

1961 Ifs and cans. In Austin, J. L., Philosophical Papers ( $3^{\text {rd }}$ edition, 1979, edited by J. O. Urmson and G. J. Warnock). Cambridge: Cambridge University Press, 153-180.

Bhatt, Rajesh, and Roumyana Pancheva

2006 Conditionals. In The Blackwell Companion to Syntax, Vol. 1, Martin Everaert, and Henk van Riemsdijk (eds.), 638-687. Oxford: Blackwell.

Comrie, Bernard

1986 Conditionals: A typology. In On Conditionals, Elizabeth Closs Traugott, Alice ter Meulen, Judy Snitzer Reilly, and Charles A. Ferguson (eds.), 77-99. Cambridge: Cambridge University Press.

Dancygier, Barbara, and Eve Sweetser

1997 Then in conditional constructions. Cognitive Linguistics 8-2: 109136.

Declerck, Renaat, and Susan Reed

2001 Conditionals, A Comprehensive Empirical Analysis. Berlin: Mouton de Gruyter.

Fauconnier, Gilles

1994 Mental Spaces. Aspects of meaning construction in natural language. Cambridge: Cambridge University Press. [1 $1^{\text {st }}$ Edition, 1985, Cambridge: The MIT Press.

Geis, Michael, and Arnold M. Zwicky

1971 On invited inferences. Linguistic Inquiry 2: 561-566.

Greenberg, Joseph H.

1963 Some universals of grammar with particular reference to the order of meaningful elements. In Universals of language, Joseph H. Greenberg (ed.). Cambridge, Mass.: MIT Press.

Haiman, John

1978 Conditionals are topics. Language 54: 565-589. 
1986 Constraints on the form and meaning of the protasis. In On Conditionals, Elizabeth Closs Traugott, Alice ter Meulen, Judy Snitzer Reilly, and Charles A. Ferguson (eds.), 215-227. Cambridge: Cambridge University Press.

Iatridou, Sabine

1994 On the contribution of conditional then. Natural Language Semantics 2: 171-199.

Johnson-Laird, P. N.

1986 Conditionals and mental models. In On Conditionals, Elizabeth Closs Traugott, Alice ter Meulen, Judy Snitzer Reilly, and Charles A. Ferguson (eds.), 55-75. Cambridge: Cambridge University Press.

König, Ekkehard

1988 Concessive connectives and concessive sentences: cross-linguistic regularities and pragmatic principles. In Explaining Language Universals, John A. Hawkins (ed.), 145-166. Oxford: Basil Backwell.

Levinson, Stephen C.

2000 Presumptive Meanings - The Theory of Generalized Conversational Implicature, Cambridge, MA : MIT Press.

Lycan, William G.

2001 Real Conditionals. Oxford: Oxford University Press.

Masica, Colin P.

1991 The Indo-Aryan Languages. (Cambridge Language Surveys) Cambridge: Cambridge University Press.

McGregor, Ronald Stuart

1995 Outline of Hindi Grammar. Oxford: Oxford University Press.

Monatut, Annie

2004 A Grammar of Hindi. (LINCOM Studies in Indo-European Linguistics) Munich: Lincom Europa.

Oranskaya, Tatyana I.

2005 Conditional constructions in Hindi. In Typology of Conditional Constructions, Victor S. Xrakovskij (ed.), 218-245. (LINCOM Studies in Theoretical Linguistics 25.) Munich: Lincom Europa.

Sharma, Ghanshyam

2008 A pragmatic account of the Hindi presumptive. In Annual Review of South Asian Languages and Linguistics, Rajendra Singh (ed.), 83113. Berlin: Mouton de Gruyter.

2010 On Hindi conditionals. In Annual Review of South Asian Languages and Linguistics, Rajendra Singh (ed.), 107-134. Berlin: Mouton de Gruyter.

Traugott, Elizabeth Closs, Alice ter Meulen, Judy Snitzer Reilly and Charles A. Ferguson (eds.)

1986 On Conditionals. Cambridge: Cambridge University Press.

Van der Auwera, Johan 
1986 Conditionals and speech acts. In On Conditionals, Elizabeth Closs Traugott, Alice ter Meulen, Judy Snitzer Reilly, and Charles A. Ferguson (eds.), 197-214. Cambridge: Cambridge University Press.

Xrakovskij, Victor S. (ed.)

2005 Typology of Conditional Constructions. (LINCOM Studies in Theoretical Linguistics 25.). Muenchen: Lincom Europa. 